\title{
Pengaruh Kepemimpinan Transformasional, Kepuasan Kerja Dan Komitmen Organisasional Terhadap Organizational Citizenship Behavior PT Sinergi
}

\author{
Roby Irzal Maulana \\ Fakultas Ekonomi Universitas Pamulang, Tangerang Selatan, Indonesia \\ robyirzalmaulana@gmail.com
}

\begin{abstract}
ABSTRAK
Tujuan penelitian ini untuk mengetahui pengaruh kepemimpinan transformasional, kepuasan kerja, dan komitmen organisasional terhadap organizational citizenship behavior. Penelitian ini menggunakan seluruh karyawan di PT Sinergi sebagai populasi. Teknik penentuan sampel yang digunakan dalam penelitian ini adalah metode sensus. Sampel yang digunakan dalam penelitian ini berjumlah 88 orang karyawan. Metode Pengumpulan data yang digunakan dalam penelitian ini menggunakan kuesioner dan wawancara. Penelitian ini menggunakan teknik analisis regresi linear berganda dengan SPSS 21.0 for windows. Hasil penelitian menunjukkan Kepemimpinan transformasional, Kepuasan kerjadan Komitmen organisasional berpengaruh positif dan signifikan terhadap organizational citizenship behavior pada karyawan di PT Sinergi. Untuk dapat meningkatkan organizational citizenship behavior, maka harus memperhatikan inspirational motivation, promotion opportunities dan komitmen afektif.

Kata kunci: kepemimpinan transformasional, kepuasan kerja, komitmen organisasional, organizational citizenship behavior
\end{abstract}

\begin{abstract}
The purpose of this study is to determine the effect of transformational leadership, work satisfaction, and organizational commitment of organizational citizenship behavior. The study used all employes in PT. Sinergi as population. Sampling technique usedin this study is sensus method. Sample used in this study are 88 employes. Data collection methods used in this study is kuisioner and interview. This study applied multiple linear regression analysis with SPSS 21.0 for windows. The analysis shows that transformational leadership, work satisfaction, and organizational commitment has positive and significant effect on financial performance on employes in PT. Sinergi. To improve organizational citizenship behavior, it must pay attention to inspirational motivation, promotion opportunities and commitment afektive.

Keywords: transformational leadership, work satisfaction, organizational commitment, organizational citizenship
\end{abstract}

Naskah diterima: 27-08-2020, direvisi: 12-06-2020, diterbitkan: 01-09-2020

\section{PENDAHULUAN}

Pengelolaan SDM saat ini merupakan suatu keharusan dan bukan lagi merupakan suatu pilihan apabila perusahaan ingin berkembang. Salah satu yang harus diperhatikan adalah rasa suka rela karyawan dalam membantu rekan kerja di luar tanggung jawab. Perasaan itu sudah dimiliki karyawan, maka kinerja perusahaan akan semakin 
meningkat dan karyawan akan merasa puas dalam melakukan pekerjaan (Robbins, 2013:23) Untuk dapat mengelola SDM dengan baik, setiap pemimpin dan manajer serta bagian yang menangani SDM harus mengerti masalah manajemen SDM dengan baik pula (Widodo, 2015). Organizational Citizenship Behavior merupakan perilaku ekstra yang tidak menjadi bagian dari kewajiban kerja formal seorang pegawai, namun mendukung berfungsinya perusahaan secara efektif (Robbins, 2009:40).

Memiliki karyawan yang bersedia mencurahkan segenap kemampuan demi kepentingan perusahaan adalah harapan bagi semua organisasi. Karyawan adalah sebagai modal utama bagi perusahaan oleh sebab itu karyawan perlu dikelola agar tetap menjadi produktif akan tetapi dalam pengelolaannya bukanlah hal yang mudah, karena karyawan mempunyai pikiran, status, serta latar belakang yang berbeda. Karyawan yang dapat bertanggung jawab atas pekerjaan yang dilakukan, sedangkan perusahaan diharapkan dapat memberikan penghargaan atau pengakuan atas prestasi karyawan. Dalam dunia kerja yang semakin berkembang dan dinamis, dimana tugas-tugas yang semakin banyak dilakukan dalam tim, lebih fleksibel, bernilai penting, diperlukan adanya karyawan yang mampu berperilaku diluar peran. Beberapa contoh seperti: membuat pernyataan yang konstruksif untuk tugas kelompok kerja mereka dan perusahaan, membantu yang lain dalam timnya, menjadi relawan untuk aktivitas tugas ekstra, menghindari konflik yang tidak perlu, menunjukan kepedulian, menghormati dan memaklumi beban dan gangguan terkait kerja yang kadang terjadi.

Kondisi tersebut membuat perusahaan sangat memerlukan karyawan yang bersedia melakukan hal yang bukan menjadi tugasnya. Srirang dan Shweta (2010) menyatakan bahwa OCB ditandai dengan usaha dalam bentuk apapun yang dilakukan berdasarkan kebijaksanaan pegawai yang memberikan manfaat bagi organisasi tanpa mengharapkan imbalan apapun. Menurut Podsakoff et al., (dalam Maria Wikantari, 2014) manfaat OCB terhadap perusahaan adalah dapat membantu meningkatkan produktivitas rekan kerja, dapat membantu meningkatkan produktivitas manajer, dapat membantu mengefisienkan penggunaan sumber daya perusahaan untuk tujuan-tujuan produktif, dapat membantu menghemat energi sumber daya yang langka untuk memelihara fungsi kelompok, dapat dijadikan sebagai sarana efektif untuk mengkoordinasi aktivitas-aktivitas antar anggota-anggota tim dan antar kelompok-kelompok kerja, dapat meningkatkan kemampuan perusahaan untuk mendapatkan dan mempertahankan sumber daya-sumber daya yang andal dengan memberikan kesan bahwa perusahaan merupakan tempat bekerja yang lebih menarik, dapat meningkatkan stabilitas kinerja perusahaan dan dapat meningkatkan kemampuan perusahaan untuk beradaptasi terhadap perubahanperubahan lingkungan bisnisnya.

Penelitian ini berusaha memperluas pemahaman mengenai pengaruh Organizational Citizenship Behavior (OCB) pada karyawan PT. Sinergi. Organ et al. (2006) mendefinisikan OCB sebagai perilaku individual yang bersifat bebas, yang tidak secara langsung dan eksplisit mendapat penghargaan dari sistem imbalan formal, dan yang secara keseluruhan (agregat) meningkatkan efisiensi dan efektifitas fungsi-fungsi perusahaan, bersifat bebas dan sukarela karena perilaku tersebut tidak diharuskan oleh persyaratan peran atau deskripsi jabatan yang secara jelas dituntut berdasarkan kontrak dengan perusahaan, melainkan sebagai pilihan personal. PT. Sinergi adalah perusahaan penyedia alatalat kesehatan. PT. Sinergi merupakan salah satu dari banyak perusahaan penyedia alat-alat kesehatan untuk operasi di Indonesia. PT. Sinergi dapat dipastikan sangat memerlukan karyawan yang memiliki peran ekstra di luar 
pekerjaannya untuk dapat mengoptimalkan kinerja karyawan di PT. Sinergi. Kepemimpinan transformasional merupakan faktor penting yang mempengaruhi OCB. Kepemimpinan transformasional yaitu pemimpin yang mencurahkan perhatiannya kepada persoalan-persoalan yang dihadapi oleh para pengikutnya dan kebutuhan pengembangan dari masing-masing pengikutnya dengan cara memberikan semangat dan dorongan untuk mencapai tujuannya (Robbins, 2007). Menurut Koesmono (2013) kepemimpinan transformasional adalah pemimpin yang memberikan pertimbangan dan rangsangan intelektual yang diindividualkan dan memiliki kharisma. Abu dan Al'omari (2008).

Memberikan pedoman khusus untuk mengimplementasikan faktor pengaruh individu yang mungkin membantu memecahkan masalah dan meningkatkan gaya kepemimpinan transformasional pada diri karyawan antara lain, menggerakkan semua sumber daya kekuatan organisasi, menciptakan perbedaan dan perubahan besar dalam organisasi dan membesarkan kolegasubordinate untuk mencapai kesadaran yang lebih besar atas perannya dalam organisasi.

Penelitian Saeed dan Ahmad (2012) menyatakan dengan mengadopsi gaya kepemimpinan transformasional untuk mempengaruhi bawahannya sehingga mereka dapat terlibat dalam perilaku ekstra peran seperti OCB yang bermanfaat bagi pertumbuhan organisasi. Maharani dkk (2013) menyatakan kepemimpinan transformasional mempunyai pengaruh positif yang tidak langsung terhadap OCB. Secara umum OCB muncul diakibatkan karena karyawan mendapatkan

kepuasan bekerja pada suatu organisasi. Kepuasan kerja merupakan suatu perasaan positif tentang pekerjaan seseorang yang merupakan hasil dari evaluasi karakteristiknya (Ivancevich et al., 2006). Sakiru et al., (2013) menjelaskan kepuasan kerja merupakan hal terpenting bagi pekerja untuk pengembangan organisasi, pekerja berharap mendapatkan lebih banyak kepuasan dengan pekerjaan mereka daripada dimasa lalu. Menurut Teori Herzberg, terdapat dua faktor yang menyebabkan kepuasan dan ketidakpuasan yaitu, faktor motivator merupakan karakteristik pekerjaan berkaitan dengan kepuasan pekerjaan, yaitu jumlah kebutuhan yang apabila dipenuhi akan menimbulkan keputusan tetapi jika tidak dipenuhi akan mengurangi kepuasan, faktor hygiene merupakan karakteristik pekerjaan berkaitan dengan ketidakpuasan pekerjaan, yaitu sejumlah kebutuhan yang apabila dipenuhi tidak akan meningkatkan motivasi, tetapi jika tidak dipenuhi akan menimbulkan kepuasan.

Menurut Podsakof et al., (dalam Achmad Sani, 2013) mengungkapkan bahwa karyawan yang puas umumnya lebih mudah untuk melakukan kontribusi yang lebih (OCB). Ketika karyawan merasakan kepuasan terhadap pekerjaan yang dilakukannya, maka karyawan tersebut akan bekerja secara maksimal dalam menyelesaikan pekerjaannya, bahkan melakukan beberapa hal yang mungkin diluar tugasnya.

Komitmen organisasional merupakan salah satu faktor penting yang berperan dalam membentuk OCB karyawan. Menurut Thamrin et al., (2011) komitmen karyawan merupakan suatu bentuk identifikasi, loyalitas dan keterlibatan yang diekspresikan oleh karyawan terhadap organisasi. Karyawankaryawan yang merasa lebih berkomitmen pada organisasi memiliki kebiasaankebiasaan yang bisa diandalkan, berencana untuk tinggal lebih lama di dalam organisasi, dan mencurahkan lebih banyak upaya dalam bekerja (Lamidi, 2009).

Komitmen organisasional merupakan sikap yang merefleksikan loyalitas karyawan pada perusahaan dan proses berkelanjutan dimana anggota organisasi mengekspresikan perhatiannya terhadap organisasi pada keberhasilan dan kemajuan yang berkelanjutan. Wagner dan Rush (2000) menemukan komitmen organisasional berpengaruh pada OCB. 
Nagar (2012) memberikan pedoman khusus untuk mengimplementasikan sistem manajemen yang mungkin membantu memecahkan masalah dan meningkatkan komitmen organisasional pada diri karyawan yaitu, berkomitmen pada nilai utama manusia dilakukan dengan membuat aturan tertulis, mempekerjakan manajer yang baik dan tepat mempertahankan komunikasi, memperjelas dan mengomunikasikan misi, memperjelas misi dan ideologi, karisma menggunakan praktik perekrutan berdasarkan nilai, menekankan orientasi berdasarkan nilai stres dan pelatihan, membentuk tradisi berdasarkan nilai, menekankan orientasi berdasarkan nilai stres dan pelatihan, membentuk tradisi, menjamin keadilan organisasi, memiliki prosedur penyampaian keluhan yang komprehensif, menyediakan komunikasi dua arah yang ekstensif, menciptakan rasa komunitas membangun homogenitas berdasarkan nilai, keadilan, menekankan kerja sama, saling mendukung, dan mendukung perkembangan karyawan melakukan aktualisasi; memberikan pekerjaan menantang pada tahap pertama; memajukan dan memberdayakan; mempromosikan dari dalam; menyediakan aktivitas perkembangan; menyediakan keamanan kepada karyawan.

(Lamidi, 2009) Menemukan hubungan positif antara komitmen afektif dan komitmen normatif terhadap OCB, dimana komitmen normatif mempunyai hubungan yang lebih kuat dari pada komitmen afektif, sementara komitmen berkelanjutan mempunyai hubungan yang negatif terhadap kepatuhan. Berdasarkan hasil wawancara yang telah dilakukan terhadap beberapa karyawan di PT. Sinergi terdapat masalah yaitu rendahnya Organizational Citizenship Behavior yang ditandai dengan karyawan yang hanya mengerjakan tugas dan tanggungjawabnya sendiri serta tidak memiliki keinginan untuk membantu rekan kerja yang memiliki beban kerja yang berlebihan.
Rendahnya OCB di PT. Sinergi tidak luput dari rendahnya kepemimpinan transformasional, kepuasan kerja dan komitmen organisasional. Indikasi rendahnya kepemimpinan transformasional di PT. Sinergi dimana pemimpin kurang berinteraksi langsung kepada karyawan dan memberikan semangat langsung kebawahan.

Indikasi rendahnya kepuasan kerja karyawan dimana beberapa karyawan masih sering mengeluh dengan sistem penggajian yang dirasa masih kurang dan tidak sesuai dengan pekerjaan yang telah dilakukan, kurangnya kesempatan promosi dan kurangnya pengawasan dari atasan terhadap bawahan. Masalah komitmen organisasional di PT. Sinergi menjadi suatu hal yang penting. Adapun masalah komitmen organisasional yang ditemui di PT. Sinergi seperti karyawan selalu mengeluh dan tidak mau terlibat dalam hal yang mendukung tujuan perusahaan dan kurangnya rasa kekeluargaan dalam perusahaan yang menyebabkan beberapa karyawan kurang merasa nyaman tinggal dalam perusahaan.

Berdasarkan uraian yang sudah dijelaskan, maka penelitian ini meneliti tentang "Pengaruh Kepemimpinan Transformasional, Kepuasan Kerja dan Komitmen Organisasional Terhadap Organizational Citizenship Behavior PT. Sinergi.

Hasil penelitian Lamidi (2008) menunjukan bahwa kepemimpinan transformasional mempunyai pengaruh yang signifikan terhadap OCB. Menurut Moghimi et al., (2013) menyatakan bahwa kepemimpinan transformasional mempunyai pengaruh yang positif dan signifikan terhadap OCB. Penelitian yang dilakukan oleh Nguni (2005) pada sekolah-sekolah dasar dan sekolah menengah di Tanzania juga menunjukkan pengaruh yang signifikan dan positif antara kepemimpinan transformasional terhadap perilaku OCB dari para guru. Berdasarkan latar belakang dan pokok permasalahan yang telah diuraikan, maka 
dapat dikemukakan hipotesis sebagai berikut.

H1: Kepemimpinan transformasional berpengaruh positif dan signifikan terhadap OCB.

Pernyataan ini diperkuat oleh Krishnan $e t$ al., (2009) menunjukkan bahwa baik kepuasan kerja intrinsik maupun kepuasan kerja ekstrinsik berpengaruh signifikan terhadap OCB. Murphy et al., (2002) menemukan bahwa kepuasan kerja memiliki hubungan yang signifikan dan positif terhadap OCB. Ngadiman et al., (2013) menyatakan kepuasan kerja mempunyai pengaruh yang signifikan terhadap OCB. Ini berarti bahwa lebih tinggi kepuasan kerja yang mereka peroleh maka lebih tinggi OCB dalam pribadi pengajarannya. Sedangkan penelitian yang dilakukan Yoon dan Suh (2003) menemukan bahwa kepuasan kerja berpengaruh positif signifikan terhadap OCB. Selanjutnya, Osman et al., (2015) menemukan kepuasan kerja memiliki hubungan positif dengan OCB. Berdasarkan latar belakang dan pokok permasalahan yang telah diuraikan, maka dapat dikemukakan hipotesis sebagai berikut.

$\mathrm{H} 2$ : Kepuasan kerja berpengaruh positif dan signifikan terhadap OCB.

Hasil penelitian sebelumnya oleh Merry (2013) yang menyatakan bahwa komitmen organisasional mempunyai pengaruh positif dan signifikan terhadap OCB karyawan Rumah Sakit Bhayangkara Trijata Denpasar. Zeinabadi (2010) menemukan bahwa komitmen organisasional mempunyai pengaruh yang signifikan terhadap OCB. Darmawati et al., (2013) menemukan bahwa komitmen organisasional memiliki hubungan yang signifikan terhadap OCB. Selanjutnya, Kim (2006) menemukan bahwa afektif komitmen berpengaruh positif pada OCB.

Berdasarkan latar belakang dan pokok permasalahan yang telah diuraikan, maka dapat dikemukakan hipotesis sebagai berikut

H3: Komitmen organisasional berpengaruh positif dan signifikan terhadap OCB.

\section{MODEL PENELITIAN}

Berdasarkan kajian terhadap studi-studi terdahulu baik secara konsep maupun empiris, maka dapat disusun suatu model penelitian seperti yang ditunjukan pada Gambar 1.

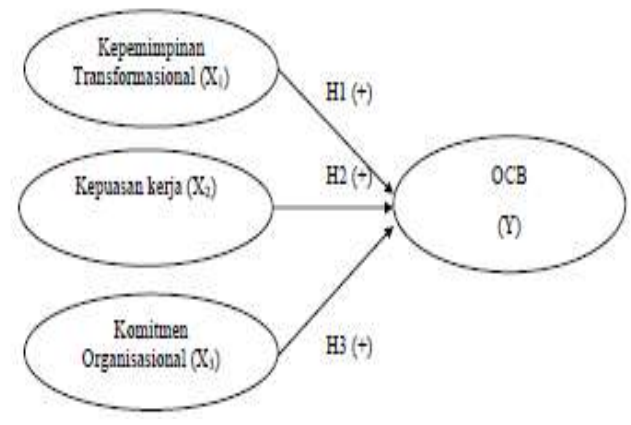

Gambar 1. Kerangka Berfikir Penelitian

Desain penelitian ini menggunakan metode dan kuantitatif yang berdasarkan bentuk tingkat eksplanasi penelitian yaitu berbentuk penelitian asosiatif yang memiliki hubungan kausal. Penelitian ini dilakukan di PT. Sinergi yang beralamat di Green Office Park lantai 3 gedung my republic BSD City. Alasan peneliti melakukan penelitian di PT. Sinergi yaitu karena ditemukannya masalah yang terkait Organizational Citizenship Behavior di PT. Sinergi. Adapun objek dari penelitian ini adalah kepemimpinan transformasional, kepuasan kerja, komitmen organisasional dan Organization Citizenship Behavior di PT. Sinergi. Variabel terikat dalam penelitian ini adalah Organizational Citizenship Behavior (Y). Adapun indikator yang digunakan adalah sebagai berikut (Organet al., 2006): altruism (Y1), conscientiousness (Y2), sportmanship (Y3), courtesy (Y4) dan civic virtue (Y5). Variabel bebas dalam penelitian ini adalah kepemimpinan transformasional (X1), kepuasan kerja (X2) dan komitmen organisasional (X3). Menurut Robbins dan Judge (2008) variabel kepemimpinan transformasional diukur dengan menggunakan indikator sebagai berikut: idealized influence (X1.1), inspirational motivation (X1.2), intellectual stimulation (X1.3), dan individual consideration (X1.4). 
Robbins dan Judge (2008); Azeem (2010) mengungkapkan bahwa terdapat lima indikator kepuasan kerja, yaitu: pembayaran (X2.1), pekerjaan (X2.2), kesempatan promosi (X2.3), atasan $(\mathrm{X} 2.4)$, dan rekan kerja (X2.5), Komitmen organisasional merupakan orientasi hubungan aktif antara individu dan organisasinya. Adapun indikatornya menurut Zulpikar dan Daniel (2011) terdiri dari: affective commitment (X3.1), continuance commitment (X3.2) dan normative commitment (X3.3).

Data kuantitatif dari penelitian ini adalah jumlah pegawai di PT. Sinergi dan data kualitatif dalam penelitian ini seperti struktur organisasi dan sejarah singkat PT. Sinergi Tridaya Medical. Dalam penelitian ini anggota populasi adalah seluruh karyawan di PT. Sinergi.

Metode penarikan sampel yang digunakan dalam penelitian ini adalah dengan menggunakan teknik sampling jenuh (Metode Sensus) yang merupakan teknik menentukan sampel bila semua anggota populasi digunakan sebagai sampel (Sugiyono, 2012). Berdasarkan pengertian tersebut maka yang menjadi responden dalam penelitian ini adalah 88 karyawan dengan tidak mengikutsertakan Kepala Cabang di PT. Sinergi.

Metode pengumpulan data yang dilakukan yakni: menggunakan tanya jawab langsung dengan pihak-pihak yang terkait dalam penelitian yang dilakukan, seperti melalui wawancara dengan beberapa pegawai di PT. Sinergi dan pernyataan secara tertulis mengenai kepemimpinan transformasional, kepuasan kerja, komitmen organisasional dan OCB di PT. Sinergi.

Skala yang digunakan dalam pengukuran data adalah menggunakan skala likert untuk mengukur sikap, sifat, pendapat atau presepsi seseorang atau sekelompok orang tentang fenomena sosial (Sugiyono, 2012; 132). Untuk menguji instrument penelitian maka dilakukan uji validitas, uji Reliabilitas dan Analisis faktor konfirmatori. Uji validitas dilakukan dengan cara menghitung korelasi antar skor masing-masing pertanyaan. Jika koefisien korelasi positif dan lebih besar dari 0,3 maka indikator dikatakan valid (Sugiyono, 2012:178). Uji Validitas adalah untuk menguji seberapa baik instrumen penelitian dalam mengukur konsep yang seharusnya diukur (Sugiyono, 2012:172). Instrumen yang reliabel adalah instrumen yang apabila digunakan beberapa kali untuk mengukur obyek yang sama akan menghasilkan data yang sama (Sugiyono, 2012:173). Teknik CFA ditujukan untuk mengestimasi measurement model, menguji unidimensionalitas dari konstruk-konstruk eksogen dan endogen. Teknik analisis data yang digunakan dalam penelitian ini adalah analisis regresi linier berganda. Analisis statistik dilakukan dengan menggunakan program SPSS 21.0 for windows (Statistica Program and Service Solution) dan program Microsoft Excel. Teknik analisis data dalam penelitian ini adalah menggunakan analisis regresi linier berganda. Persamaan regresi linier berganda dirumuskan secara sistematis sebagai berikut:

$\hat{Y} 111223331 \quad \square \square a \quad \square \square \square X \square \square \square X$ $\square \square \square X \square \square e$

.... (1)

Sumber : Nata Wirawan (2002)

Keterangan :

$\hat{Y}=$ Organizational Citizenship Behavior

$\mathrm{X} 1=$ Kepemimpinan Transformasional

$\mathrm{X} 2$ = Kepuasan Kerja

X3 = Komitmen Organisasional

$\mathrm{a}=$ Konstanta

$\beta 1 \beta 2 \beta 3=$ Koefisien dari variabel bebas $\mathrm{e} 1=$ Koefisien pengganggu .

\section{PEMBAHASAN}

Penelitian ini dilakukan untuk mengetahui pengaruh kepemimpinan transformasional, kepuasan kerja dan komitmen organisasional terhadap OCB di PT. Sinergi. Data karakteristik responden merupakan data responden yang dikumpulkan untuk mengetahui profil responden penelitian. Dari hasil 
penelitian yang dilakukan pada karyawan di PT. Sinergi, maka diketahui karakteristik responden yang meliputi tiga aspek, yaitu tingkat pendididkan, umur serta jenis kelamin responden. Kuisioner yang disebarkan kepada responden sebanyak 88 kuisioner. Jadi, responden yang digunakan pada karakteristik responden adalah sebanyak 88 orang.

Tabel 1.

Karateristik Responden

\begin{tabular}{|c|c|c|c|}
\hline \multirow{2}{*}{$\mathrm{No}$} & \multirow{2}{*}{$\begin{array}{l}\text { Vur } \\
\text { (12brn) }\end{array}$} & \multicolumn{2}{|c|}{ Imlà } \\
\hline & & Oang & Privena (8) \\
\hline I & 5MA & 42 & 47,7 \\
\hline 2 & $\mathrm{DI}$ & $\theta$ & 0 \\
\hline 3 & DS & 0 & $\theta$ \\
\hline 4 & $\$ 1$ & 43 & 419 \\
\hline \multirow[t]{2}{*}{5} & 52 & 3 & 34 \\
\hline & Junlah & 88 & 100 \\
\hline \multirow{2}{*}{$\mathrm{N}_{2}$} & Vur & \multicolumn{2}{|c|}{ fandai } \\
\hline & (7igra) & Ozag & Pessensa (4) \\
\hline 1 & 2125 & 16 & 18,1 \\
\hline 2 & $25-30$ & 12 & 137 \\
\hline 3 & $30-35$ & 17 & 193 \\
\hline 4 & $35-4:$ & 13 & 148 \\
\hline \multirow[t]{2}{*}{5} & $\rightarrow 0$ & 30 & 34,1 \\
\hline & Jumlat & 88 & 100 \\
\hline \multirow{2}{*}{$\mathrm{Ni}$} & \multirow{2}{*}{$\begin{array}{l}\text { Vurr } \\
\text { (Tibra) }\end{array}$} & \\
\hline & & Oeng & $\underbrace{}_{\text {Perculat }}$ \\
\hline I & Liki-khi & 43 & 439 \\
\hline 2 & Peraprous & 45 & 521 \\
\hline & Junlat & 38 & 5 \\
\hline
\end{tabular}

Sumber: Data Primer Diolah

Responden pada penelitian di PT. Sinergi Tridaya Medical, sebagian besar memiliki tingkat pendiddikan S1 dengan jumlah 43 orang dengan presentase sebesar 48,9 persen, hal ini dikarenakan sebagian besar karyawan PT. Sinergi mengikuti rekrutmen pada jenjang pendidikan S1. Untuk usia responden pada PT. Sinergi ini sebagian besar berusia lebih dari 40 tahun, yaitu sebanyak 30 orang atau sebesar 34,1 persen. Kemudian jenis kelamin responden pada PT. Sinergi didominasi oleh karyawan perempuan yaitu sebanyak 45 orang atau 51,1 persen.
Tabel 2.

Hasil Perhitungan Uji Validitas

\begin{tabular}{|c|c|c|c|c|c|}
\hline \multirow[b]{2}{*}{ No. } & \multirow[b]{2}{*}{ Variabel } & \multirow[b]{2}{*}{ Item } & \multicolumn{2}{|c|}{ Validitas } & \multirow[b]{2}{*}{ Keterangan } \\
\hline & & & $\begin{array}{l}\text { Koefisien } \\
\text { Korelasi }\end{array}$ & Standar & \\
\hline \multirow[t]{4}{*}{1} & \multirow{4}{*}{$\begin{array}{l}\text { Kepemimpinan } \\
\text { transformasional (Xl) }\end{array}$} & $\mathrm{X} 1.1$ & 0,853 & 0,3 & Valid \\
\hline & & $\mathrm{X} 1.2$ & 0,903 & 0,3 & Valid \\
\hline & & $\mathrm{X} 1.3$ & 0,948 & 0,3 & Valid \\
\hline & & $\mathrm{X} 1.4$ & 0,901 & 0.3 & Valid \\
\hline \multirow[t]{5}{*}{2} & \multirow[t]{5}{*}{ Kepuasan kerja (X2) } & $\mathrm{X} 2.1$ & 0,840 & 0,3 & Valid \\
\hline & & $\mathrm{X} 2.2$ & 0,870 & 0,3 & Valid \\
\hline & & $\mathrm{X} 2.3$ & 0,826 & 0,3 & Valid \\
\hline & & $\mathrm{X} 2.4$ & 0,740 & 0,3 & Valid \\
\hline & & $\mathrm{X} 2.5$ & 0,851 & 0,3 & Valid \\
\hline \multirow[t]{3}{*}{3} & \multirow{3}{*}{$\begin{array}{l}\text { Komitmen Organisasional } \\
\text { (X3) }\end{array}$} & $\mathrm{X} 2.1$ & 0,920 & 0,3 & Valid \\
\hline & & $\mathrm{X} 2.2$ & 0,828 & 0,3 & Valid \\
\hline & & $\mathrm{X} 2.3$ & 0,899 & 0,3 & Valid \\
\hline \multirow[t]{5}{*}{4} & \multirow[t]{5}{*}{$O C B(Y)$} & $\mathrm{Y} 1$ & 0,833 & 0,3 & Valid \\
\hline & & $\mathrm{Y} 2$ & 0,823 & 0,3 & Valid \\
\hline & & $\mathrm{Y} 3$ & 0,822 & 0,3 & Valid \\
\hline & & $\mathrm{Y} 4$ & 0,816 & 0,3 & Valid \\
\hline & & Y5 & 0,866 & 0,3 & Valid \\
\hline
\end{tabular}

Sumber: Data Primer Diolah

Tabel 2 menunjukan bahwa seluruh indikator pernyataan dalam variable kepemimpinan transformasional, kepuasan kerja, komitmen organisasional dan organizational citizenship behavior memiliki korelasi item total lebih dari 0,3 yaitu sehingga seluruh indikator tersebut telah memenuhi syarat validitas data.

Tabel 3.

Hasil Perhitungan Uji Reliabilitas

\begin{tabular}{|c|c|c|c|c|c|}
\hline \multirow[b]{2}{*}{ No. } & \multirow[b]{2}{*}{ Variabel } & \multirow[b]{2}{*}{ Item } & \multicolumn{2}{|c|}{ Reliabilitas } & \multirow[b]{2}{*}{ Keterangan } \\
\hline & & & $\begin{array}{c}\text { Alpha } \\
\text { Cronbach }\end{array}$ & Standar & \\
\hline 1 & Kepemimpinan transformasional & $\mathrm{Xl}$ & 0,921 & 0,6 & Reliabel \\
\hline 2 & Kepuasan kerja & $\mathrm{X} 2$ & 0,881 & 0,6 & Reliabel \\
\hline 3 & Komitmen Organisasional & $\mathrm{X}_{3}$ & 0,856 & 0,6 & Reliabel \\
\hline 4 & $O C B$ & $\mathrm{Y}$ & 0,888 & 0,6 & Reliabel \\
\hline
\end{tabular}

Sumber: Data Primer Diolah

Uji normalitas dengan menggunakan uji non parametrik satu sampel KolmogorovSmirnov bertujuan untuk meyakinkan apakah residual dapat terdistribusi dengan normal dan independen.

Tabel 4.

Hasil Uji Normalitas

\begin{tabular}{cc}
\hline & Unstandardized Residual \\
\cline { 2 - 3 } NI & 88 \\
\hline Kolmogorov-Smimov Z & 0,845 \\
\hline Asymp.Sig.(2-taniod) & 0,473 \\
\hline Sum
\end{tabular}

Sumber: Data Primer Diolah

Tabel 4 menunjukkan bahwa nilai Kolmogorov smirnov (K-S) sebesar 0,845 , sedangkan nilai asymp.Sig. (2- 
tailed) sebesar 0,473. Hasil tersebut mengidentifikasikan bahwa model persamaan regresi tersebut berdistribusi normal karena asymp.Sig. (2-tailed) 0,473 lebih besar dari nilai alpha 0,05 .

Tabel 5 .

Hasil Uji Multikolenieritas

\begin{tabular}{lcc}
\hline \multicolumn{1}{c}{ Varabel } & Tolerance & VIF \\
\hline Kepenimpinan Transfomasional $\left(\mathrm{X}_{\mathrm{l}}\right)$ & 0,317 & 3,152 \\
Kepuasan Kerja $\left(\mathrm{X}_{2}\right)$ & 0,248 & 4,037 \\
Komitmen Organisasional $\left(\mathrm{X}_{3}\right)$ & 0,321 & 3,113 \\
\hline
\end{tabular}

Sumber: Data Primer Diolah

Berdasarkan Tabel 5 dapat dilihat bahwa nilai tolerance variable kepemimpinan transformasional, kepuasan kerja dan komitmen organisasional tidak ada yang kurang dari 10 persen $(0,1)$ dan seluruh variabel bebas memiliki nilai VIF kurang dari 10. Sehingga dapat disimpulkan bahwa pada data penelitian ini, tidak terjadi multikolinearitas antara variabel bebas dalam model regresi ini.

Tabel 6.

\begin{tabular}{|c|c|c|c|c|c|}
\hline \multirow[t]{2}{*}{ Model } & \multicolumn{2}{|c|}{$\begin{array}{c}\text { Unstandardized } \\
\text { Coefficients }\end{array}$} & \multirow{2}{*}{$\begin{array}{c}\begin{array}{l}\text { Standardized } \\
\text { Coefficients }\end{array} \\
\text { Beta }\end{array}$} & \multirow[t]{2}{*}{$\mathrm{T}$} & \multirow[t]{2}{*}{ Sig. } \\
\hline & $B$ & Std. Error & & & \\
\hline (Constant) & 0,308 & 0,209 & & 10,691 & 0,000 \\
\hline $\mathrm{XI}$ & 0,017 & 0,051 & 0,62 & 0,324 & 0,747 \\
\hline $\mathrm{X} 2$ & 0,001 & 0,058 & 0,002 & 0,010 & 0,992 \\
\hline $\mathrm{X} 3$ & $-0,058$ & 0,051 & $-0,215$ & $-1,135$ & 0,260 \\
\hline
\end{tabular}

Sumber: Data Primer Diolah

Pada Tabel 6 dapat dilihat bahwa nilai Sig. Dari variabel kepemimpinan transformasional, kepuasan kerja dan komitmen organisasional masing-masing sebesar 0,747, 0,992 dan 0,260. Nilai tersebut lebih besar dari 0,05 yang berarti tidak terdapat pengaruh antara variabel bebas terhadap absolute residual. Dengan demikian, model yang dibuat tidak mengandung gejala heterokedasitas. Uji-t dilakukan untuk mengetahui seberapa besar pengaruh variabel bebas terhadap variabel terikat secara parsial. Uji-t dilakukan dengan membandingkan nilai signifikan yang dihasilkan dengan alpha 0,05 .
Tabel 7.

Hasil Uji Regresi Linier Berganda

\begin{tabular}{|c|c|c|c|c|}
\hline Koefisien & $\begin{array}{l}\text { Unstandardized } \\
\text { Coefficients Beta }\end{array}$ & $\begin{array}{l}\text { Standardized } \\
\text { Coefficients Beta }\end{array}$ & $t$ & $\begin{array}{l}\text { Signifilkans } \\
\mathrm{i}\end{array}$ \\
\hline Koustanta (a) & 0,000 & & 0,000 & 1 \\
\hline $\begin{array}{l}\text { Kepemimpinan } \\
\text { transformasional }\left(\mathrm{x}_{\mathrm{l}}\right)\end{array}$ & 0,374 & 0,374 & 4,696 & 0,000 \\
\hline Kepuasan kerja $\left(\mathrm{x}_{2}\right)$ & 0,297 & 0,297 & 3,299 & 0,001 \\
\hline $\begin{array}{l}\text { Komitmen } \\
\text { organisasional }(\mathrm{x})\end{array}$ & 0,313 & 0,313 & 3,962 & 0,000 \\
\hline
\end{tabular}

Sumber: Data Primer Diolah

$\hat{\mathrm{Y}}=0,000+0,374 \mathrm{X} 1+0,297 \mathrm{X} 2$ $+0,313 \mathrm{X} 3$.

Dimana :

$\hat{\mathrm{Y}}=$ Organizational Citizenship Behavior

$\mathrm{X} 1=$ Kepemimpinan Transformasional

$\mathrm{X} 2$ = Kepuasan Kerja

X3 = Komitmen Organisasional

Hasil pengujian hipotesis variabel kepemimpinan transformasional terhadap organizational citizenship behavior diperoleh Sig.t sebesar 0,000 dengan koefisien beta 0,374 . Tingkat signifikansi $0,000<0,05$ mengindikasikan bahwa kepemimpinan transformasional berpengaruh positif dan signifikan terhadap organizational citizenship behavior. Artinya apabila kepemimpinan transformasional meningkat, maka organizational citizenship behavior karyawan

akan mengalami peningkatan juga. Berdasarkan hal tersebut maka hipotesis kepemimpinan transformasional berpengaruh positif terhadap organizational citizenship behavior dapat diterima. Pengujian hipotesis ini mengembangkan penelitian yang dilakukan sebelumnya oleh Lamidi (2008), Moghimi et al,.(2013), dan Nguni (2005), menunjukan bahwa kepemimpinan transformasional mempunyai pengaruh yang signifikan terhadap OCB.

Hasil tersebut mengindikasikan bahwa perilaku pemimpin yang mampu 
menyampaikan visi misi organisasi secara jelas, menginspirasi bawahan, merangsang kreatifitas bawahan dan mampu melatih bawahan akan meningkatkan perilaku OCB karyawan. Perilaku OCB yang meningkat ditandai dengan meningkatnya perilaku membantu rekan sekerja dengan sukarela, patuh terhadap

peraturan perusahaan, tidak memberikan isu-isu yang dapat menjatuhkan karyawan lain, membatu meringankan masalah-masalah yang dihadapi sesama karyawan dan mendukung fungsi-fungsi organisasi secara professional. Perilaku OCB para karyawan dapat ditingkatkan dengan cara meningkatkan intensitas penerapan kepemimpinan transformasional Kepala Cabang.

Hasil dari penelitian ini menunjukan bahwa secara teoritis, indikator yang tertinggi terletak pada indikator inspiration motivation, sedangkan secara praktis indikator teringgi terletak pada idialized influence. Hal ini menunjukan bahwa walaupun secara teoritis inspirasi dari pimpinan dalam melaksanakan pekerjaan, namun secara praktis penyampaian visi misi dari pimpinan dapat meningkatkan semangat kerja karyawan di PT. Sinergi, sehingga semakin baik

penyampaian visi misi dari pimpinan maka semakin tinggi pula rasa optimis karyawan dalam menyelesaikan pekerjaan.

Hasil pengujian hipotesis variabel kepuasan kerja terhadap organizational citizenship behavior diperoleh nilai Sig.t sebesar 0,001 dengan koefisien beta 0,297 . Tingkat singnifikansi $0,001<0,05$ mengindikasikan bahwa kepuasan kerja berpengaruh positif dan signifikan terhadap organizational citizenship behavior. Artinya apabila kepuasan kerja meningkat, maka organizational citizenship behavior karyawan akan mengalami peningkatan juga. Berdasarkan hal tersebut maka hipotesis kepuasan kerja berpengaruh positif terhadap organizational citizenship behavior dapat diterima. Pengujian hipotesis ini mengembangkan penelitian yang dilakukan oleh Krishnan et al.,
(2009) menunjukkan bahwa baik kepuasan kerja intrinsik maupun kepuasan kerja ekstrinsik berpengaruh signifikan terhadap OCB. Murphy et al., (2002), Ngadiman et al., (2013) ,Yoon dan Suh (2003), Gonzales dan Garazo (2006) dan Osman et al.,(2015).

Hasil penelitian ini mengindikasikan bahwa para karyawan yang mendapatkan kepuasan kerja, akan memunculkan kerelaan mereka untuk melakukan pekerjan diluar deskripsi pekerjaanya. Adanya kesuaian antara upah dengan sesuai beban kerja, bekerja dengan penuh tanggung jawab, mengerjakan pekerjaan dengan baik akan dipromosikan, diperlakukan dengan baik oleh pemimpin dan menikmati bekerja dengan temanteman dalam lingkungan kerja akan meningkatkan perilaku OCB karyawan. Peningkatan nilai OCB para karyawan dapat dilakukan dengan cara meningkatkan kepuasan kerja mereka. Hasil dari penelitian ini menunjukan bahwa secara teoritis indicator tertinggi terletak pada promotion opportunities, sedangkan secara praktis indicator tertinggi terletak pada co-workers. Hal ini menunjukan bahwa walaupun secara teoritis kesempatan promosi dapat meningkatkan kualitas pekerjaan, namun secara praktis rekan kerja mampu meningkatkan kenyamanan karyawan dalam lingkungan kerja di PT. Sinergi. Sehingga semakin besar kesempatan promosi yang diberikan pada karyawan maka semakin tinggi pula kepuasan kerja yang dirasakan pada karyawan di PT. Sinergi. Hasil pengujian hipotesis variabel komitmen organisasional terhadap organizational citizenship behavior diperoleh Sig.t sebesar 0,000 dengan koefisien beta 0,313. Tingkat signifikansi $0,000<0,05$ mengindikasikan bahwa komitmen organisasional berpengaruh positif dan signifikan terhadap organisasional citizenship behavior. Artinya apabila komitmen organisasional meningkat, maka organisasional citizenship behavior karyawan akan mengalami peningkatan juga.

Berdasarkan hal tersebut maka hipotesis komitmen organisasional berpengaruh 
positif terhadap organisasional citizenship behavior dapat diterima. Pengujian hipotesis ini mengembangkan penelitian yang dilakukan oleh Merry (2013), Zeinabadi (2010), Darmawati et al., (2013), Chen dan Francesco (2003) dan Kim (2006) yang menyatakan bahwa komitmen organisasional mempunyai pengaruh positif dan signifikan terhadap OCB.

Hasil penelitian ini mengindikasikan bahwa para karyawan yang merasa bangga terhadap perusahaan, memiliki kekhawatiran jika meninggalkan perusahaan dan percaya bahwa seseorang harus loyal terhadap organisasinya. Perilaku OCB yang meningkat ditandai dengan meningkatnya perilaku ditandai dengan meningkatnya perilaku membantu rekan sekerja dengan sukarela, patuh terhadap peraturan perusahaan, tidak memberikan isu-isu yang dapat menjatuhkan karyawan lain, membatu meringankan masalah-masalah yang dihadapi sesame karyawan dan mendukung fungsi-fungsi organisasi secara professional. Perilaku OCB para karyawan dapat ditingkatkan dengan cara meningkatkan intensitas penerapan komitmen organisasional bawahan.

Hasil dari penelitian ini menunjukan bahwa secara praktis maupun secara teoritis indikator tertinggi terletak pada komitmen afektif. Sehingga semakin tinggi rasa bangga yang dimiliki seorang karyawan terhadap perusahaannya, maka semakin tinggi pula komitmen organisasional yang dimiliki karyawan di PT. Sinergi.

\section{PENUTUP}

Berdasarkan hasil analisis penelitian dan hasil pembahasan diatas, maka dapat ditarik beberapa kesimpulan yaitu: kepemimpinan transformasional berpengaruh positif signifikan terhadap organizational citizenship behavior pada karyawan di PT. Sinergi. Kepuasan kerja berpengaruh positif signifikan terhadap organizational citizenship behavior pada karyawan di PT. Sinergi. Komitmen organisasional berpengaruh positif signifikan terhadap organizational citizenship behavior pada karyawan di PT. Sinergi.

Berdasarkan hasil analisis penelitian, pembahasan dan kesimpulan terdapat beberapa saran yang dapat dipergunakan sebagai bahan pertimbangan dalam menentukan kebijakan di masa mendatang terutama yang berkaitan dengan kepemimpinan transformasional, kepuasan kerja, komitmen organisasional dan organizational citizenship behavior, antara lain: secara praktis, untuk dapat meningkatkan OCB, maka harus memperhatikan indikator inspirational motivation yang merupakan indikator dari kepemimpinan transformasional yang berkaitan dengan menginspirasi bawahan untuk selalu optimis dalam mencapai tujuan perusahaan yang dapat ditingakatkan oleh pimpinan dengan cara mengkomunikasikan harapan-harapan tinggi dari bawahannya, mempunyai visi yang tinggi bagi bawahannya, optimis dan antusias serta memberikan dorongan dan arti terhadap apa yang perlu dilakukan. Kesempatan promosi yang merupakan indikator dari kepuasan kerja berkaitan dengan mengerjakan pekerjaan dengan baik, saya akan dipromosikan ini dapat dilakukan dengan cara member kesempatan kepada karyawan untuk dapat mengembangkan kreativitas dan inofasi yang lebih baik demi tercapainya tujuan organisasi secara optimal dan continuance commitment yang merupakan indikator dari komitmen organisasional berkaitan dengan memiliki kekhawatiran jika meninggalkan perusahaan dapat ditingkatkan melalui absensi karyawan serta mengurangi rasa ketidakpuasan karyawan terhadap organisasi yang nantinya akan mampu meningkatkan OCB kryawan di PT. Sinergi. pada variabel komitmen organisasional.

Apabila indikator-indikator tersebut dapat ditingkatkan, tentunya akan lebih meningkatkan organizational citizenship behavior di PT. Sinergi. Secara teoritis, untuk dapat meningkatkan organizational citizenship behavior, maka harus 
memperhatikan indikator inspirational motivation pada variabel kepemimpinan transformasional, indikator promotion opportunities pada pada variabel kepuasan kerja dan indikator afektif pada variabel komitmen organisasi. Karena ketiga indikator tersebut memiliki nilai loading factor tertinggi dalam membentuk masing-masing variabel.

\section{REFERENSI}

Abu-Tineh, A. M., Khasawneh, S. A., \& Al-Omari, A. A.2008. Kouzes and Posner's transformational leadership model in practice: The case of Jordanian schools. Leadership \& Organization Development Journal, 29, 648 660.

https://doi.org/10.1108/0143773081 0916613

Achmad Sani. 2013. Role of Procedural Justice, Organizational Commitment and Job Satisfaction on Job Performance: The Mediating Effects of Organizational Citizenship Behavior. International Journal of Business and Management; Vol. 8, No.

https://doi.org/10.5539/ijbm.v8n15 p57

Azeem, S.M. 2010. Job Satisfaction and Organizational Commitment among Employees in the Sultanate of Oman, Journal of Psychology, Vol 1, pp. 295-299. https://doi.org/10.4236/psych.2010 .14038

Darmawati, Arum., Hidayati, Lina Nur., Herlina S., Dina. 2013. Pengaruh Kepuasan Kerja dan Komitmen Organisasi terhadap Organizational Citizenship Behavior - Jurnal Economia, 9(1), 10-17.

Ivancevich, John M. Donnelly, James H. Jr. 2006. Organizational Behavior, Structure, Process; Texas, Business Publication Inc.

Kim, Sangmook. 2006. Public service motivation and organizational citizenship behaviour in Korea. International Journal of Manpower, Vol.27 No. 8, pp. $722-$
740.

https://doi.org/10.1108/014377206 10713521

Koesmono, H. Teman. 2013. Pengaruh, Motivasi, Budaya Organisasi, Kepemimpinan

Transformasional,Transaksional

Terhadap Kepuasan Kerja dan Komitmen Organisasional Guru SMA Swasta Kristen Petra (Studi pada Workshop Leadership \& Motivation in Teaching and Transfering the Knowledge di Fakultas Bisnis Unika WidyaMandala Surabaya). Jurnal Mitra Ekonomi dan Manajemen Bisnis. Vol. 4, No. 1, April 2013, 56-68.

Krishnan R., Arumugam, N., Chandran, V., and Kanchymalay, K. 2009.Examining the Relationship between Job Satisfaction and Organizational Citizenship Behavior: A Case Study among Non Academic Staffs in A Public Higher Learning Institution in Malaysia, Global Business Summit Conference, Vol 2, No 43, pp. 221232.

Lamidi. 2008. Pengaruh Kepemimpinan Transformasional Terhadap Organizational Citizenship Behavior: Dengan Variabel Intervining Komitmen Organisasional, Jurnal Ekonomi dan Kewirausahaan, Vol.8, no. 1, 25-37.

Maharani, Vivin., Eka Afnana Troena and Noermijati. 2013. Organizational Citizenship Behavior Role in Mediating the effect of Transformational Leadership, job satisfaction on Employee Performance: Studies in PT. Bank Syariah Mandiri Malang East Java. International Journal of Business and Management. 8.17: p1.

https://doi.org/10.5539/ijbm.v8n17 p1

Maria Wikantari. 2014. Pengaruh Faktorfaktor Personality Dan Procedural Justice Terhadap Organizational 
Citizenship Behavior. Jurnal Bijak Volume. XI No. 2 September 2014

Merry Ristiana, M. 2013. Pengaruh Komitmen Organisasi Dan Kepuasan kerja Terhadap Organizational Citizenship Behavior (OCB) Dan Kinerja Karyawan Rumah Sakit Bhayangkara Trijata Denpasar. Jurnal Ilmu Ekonomi \& Manajemen, Vol. 9, No. 1, hal. 5670.

Moghimi dan Firozabad, 2013, The Mediating Effects of Psychological Empowerment and Job Satisfaction in the Relationship between Transformational Leadership and Organizational Citizenship Behavior, Journal of Basic and Applied, Vol. 3,No.5.

Murphy, G., Athanasou, J., and King, N. 2002. Job Satisfaction and Organizational Citizenship Behaviour: A study of Australian Human- Service Professionals, Journal of Managerial Psychology, Vol 17, No 4, pp. 287 297.

https://doi.org/10.1108/026839402 10428092

Nagar, K. 2012. Organizational Commitment and Job Satisfaction among Teachers during Times of Burnout. Vikalpa: The Journal for Decision Markets, 37(2). https://doi.org/10.1177/025609092 0120205

Nata Wirawan. 2002. Cara Mudah Memahami Statistik 2 (Statistik Inferensia) Untuk Ekonomi dan Bisnis. Edisi Kedua. Denpasar : Keraras Emas.

Ngadiman. 2013. Influence of Work Satisfaction, and Organizational Commitment to The Organizational Citizenship Behavior of Lecturers at Faculty of Teachers" Training and Education, Sebelas Maret University, Surakarta, Educational Research International, Vol. 1, No. 3
Nguni, S.C., 2005. A Study of the Effects of Transformational Leadership on Teachers" Job Satisfaction, Organizational Commitment and Organizational Citizenship Behaviour in Tanzanian Primary and Secondary Schools, Doctoral thesis, Universiteit Nijmegen.

Organ, D.W., Podsakoff, P.M., and MacKenzie, S.B. 2006.OrganizationalCitizenship Behavior: Its Nature, Antecedents, and Consequences, SAGEPublications.

Osman , A., Yusuf Haji Othman, S M Sohel Rana, Mohhamad Solaiman \& Bharat Lal. 2015. The Influence of Job Satisfaction, Job Motivation \& Percieved Organizational Support toward Organizational Citizenship Behavior (OCB) in Malaysia. Asian Social Science; Vol 11, No. 21 pp 174-182. https://doi.org/10.5539/ass.v11n21 p174

Robbins, Stephen P. 2009. Perilaku Organisasi, Edisi kesepuluh: ahli bahasa Benyamin Molan, Edisi Bahasa Indonesia; PT. Mancanan Jaya Cemerlang, Indonesia.

Saeed, Aamir and Shabaz Ahmad. 2012. Percieved Transformational Leadership Style and Organizational Citizenship Behavior: A Case Study Of Administrative Staff of University of the Punjob. European Journal of Business and Management. 4(21): pp: 150-158.

Sakiru, Oladipo Kolapo, Jeffrey Lewrence D'siva, Jamilah Othman, Abu Daud Silong, and Adekanye Temitope Busayo. 2013. Leadership Style and Job Satisfaction among Employees in Small and Medium Enterprises. International Journal of Business and Management, 8(13): pp: 3441. https://doi.org/10.5539/ijbm.v8n13 p34 
Shweta, J., and Srirang, J. 2010. Determinants of Organizational CitizenshipBehavior: A Review of Literature. Journal of Management and Public Policy, Vol 1 No 2, pp. 27-36.

Sugiyono. 2012. Metode Penelitian Bisnis. Bandung: Alfabeta.

Thamrin, H.M. 2012. The influence of Transformational leadership and Organization Commitment on Job Satisfaction and Employee performance. International Journal Innovation, Management and Technology, 3(5),pp: 567-672. https://doi.org/10.7763/IJIMT.201 2.V3.299

Wagner, Sharon L \& Rush, Michael C. 2000. Altruistic organizational citizenship behavior: Context, desposition, and age, The Journal of Social Psychology; Jun; 140, 3; ProQuest Medical Library pg. 379. https://doi.org/10.1080/002245400 09600478

Widodo, Suparno Eko. 2015. Manajemen Pengembangan Sumber Daya Manusia. Yogyakarta. Pustaka Pelajar.

Yoon, Mahn. Hee, Suh, Jaebeom. 2003. Organizational Citizenship Behavior and service quality as external effectiveness of contact employees. Journal of Business Research 56, 597-611. https://doi.org/10.1016/S01482963(01)00290-9

Zeinabadi, Hassanreza. 2010. Job Satisfaction and Organizational Commitment as Antecedents of Organizational Citizenship Behavior (OCB) of Teachers. Procedia Social and Behavioral Sciences, 5, 988-1003. https://doi.org/10.1016/j.sbspro.20 10.07.225

Zulpikar dan Daniel Budi Santoso. 2011. Analisis Komitmen Organisasional, Kepuasan Kerja dan Kinerja Karyawan. Jurnal Ilmu Administrasi, 8(1), pp:82-96

\section{BIODATA PENULIS}

Roby Irzal Maulana seorang dosen dari Universitas Pamulang Program Studi Manajemen dengan jabatan fungsional Asisten Ahli, beliau menempuh pendidikan formal $\mathrm{S} 1$ di Universitas Jenderal Soedirman dan S2 Magister Manajemen Di Universitas Muhammadiyah Jakarta 